\title{
Building regional governance in England: The view from Whitehall
}

Authors and affiliation

Graham Pearce, Senior Lecturer, Aston Business School, Aston University, Birmingham, B4 7ET. Telephone: Home 01564 792964, Office 0121359 3611, Ext 5055. E mail:

g.r.a.pearce@aston.ac.uk

Sarah Ayres, Research Fellow, Aston Business School, Aston University, Birmingham, B4 7ET. 


\section{Building regional governance in England: The view from Whitehall}

\section{Graham Pearce and Sarah Ayres}

Abstract: Constitutional arrangements in parts of the UK have been transformed by political devolution. In the English regions the Government has pursued a more cautious approach based upon reinforcing the regional tier through administrative decentralisation. Nonetheless, such reforms represent a significant strengthening of the machinery of regional governance and open up opportunities for the recalibration of intra-state relations. Drawing on the views of Whitehall civil servants, this article explores how central-regional relations are being adapted and how government is building a regional perspective into its activities. We conclude that the implications of increased regionalisation for government have not been fully grasped and that greater attention needs to be given to regional priorities in the development of national policies and the adoption of a more co-ordinated approach to regional strategy making and implementation.

Keywords: Decentralisation, Devolution, Whitehall, English regions, Multi-level governance

\section{Introduction}

Given the weakness of local government and the stress placed on the efficient and equitable delivery of universal services, the UK has traditionally been viewed as a classic example of a unitary state in which central institutions dominate decision-making (Richards and Smith, 2002; Smith, 1999; John, 1996). However, in responding to growing evidence that the dispersion of government across territorial tiers is more effective than central state monopoly, the Labour Government has introduced constitutional reforms which have brought about an asymmetric set of territorial structures and processes (Marks and Hooghe, 2000; Jessop, 1999). Combining central control with decentralised decision-making at the regional tier in the UK is not a new phenomenon, it was practised for many years through separate government offices for Northern Ireland, Scotland and Wales, though their capacity to reflect territorial priorities in policy or spending decisions was confined. The recent devolution settlements in the Celtic nations and the creation of a strategic authority for London, therefore, signify a radical departure, not merely the decentralisation of central government functions but the exercise of territorial self governance and participation in policy making and implementation. 
The English regions lack this legacy of territorial working and, rather than political devolution, the government has adopted a far less radical approach based upon administrative decentralisation. During Labour's first term the Government's Regional Offices (GOs) were bolstered to enable Whitehall departments to oversee the delivery of national policies at regional and local levels and Regional Development Agencies (RDAs) appointed to prepare and deliver regional economic strategies. Unelected Regional Chambers were established in 1999 to provide a mantle of regional democracy, but without legislative or policy making powers. A thick, but fragmented, layer of Non Departmental Public Bodies (NDPBs) is also present (Ayres and Pearce, 2002; House of Commons, 2001; Skelcher, 2000). In 2002 the Government published its White Paper, Your Region, Your Choice: Revitalising the English Regions, which introduced proposals to further enhance the powers of GOs, RDAs and Assemblies (Cabinet Office and DTLR, 2002). It also endorsed the creation of Elected Regional Assemblies in those regions where there is evidence of public support, expressed in referendums. In November 2004, however, $78 \%$ of electors in the first referendum in the North East rejected this opportunity, forcing the government to abandon its plans for regional government. The implication is that, for the foreseeable future, reliance will be placed on reforms to the organisation of regional governance set out in Chapter 2 of the White Paper. These gave the GOs, RDAs and Assemblies additional responsibilities for regional decisionmaking and the co-ordination of strategies and implementation frameworks, prepared by public sector stakeholders and their partners in the business and community sectors. In addition, the unelected assemblies will retain specific responsibilities for strategic spatial planning, housing and transport.

These developments can be regarded as strengthening the machinery of regional governance and evidence of the Government's continuing commitment to the reform of intra-state relations, in which decision-making and co-ordination competencies are no longer monopolised by Whitehall. In 2003 the Deputy Prime Minister declared 'I'm proud that we have shifted the balance of power away from Westminster and Whitehall and changed the culture that 'Whitehall always knows best" (Prescott, 2003). The White Paper asserted that administrative decentralisation 'will make the delivery of programmes and policies more efficient and ultimately lead to better outcomes in all regions' (Cabinet Office and DTLR, 2002: 3.14). Decentralisation also brings about the possibility of greater territorial flexibility in policy-making and reflects the widespread belief that the successful implementation of public policy 'is increasingly dependent upon a much wider array of public, private and voluntary organisations than would be included within the traditional governmental framework' (Flinders, 2002: 52). 'More than ever before, governments are dealing with other autonomous actors in order to realise their policy objectives' (Klijn, 2002: 150). In the 
UK this can be seen as a response to wide-ranging reforms including a 'de-centring outwards', through markets and quasi-market mechanisms to NDPBs and a 'de-centring down' - the decentralisation and devolution of authority to regions and localities (Pierre and Peters, 2000). Whitehall departments are increasingly expected to take account of the views of regional stakeholders and 'the Government believes that when decisions are taken with an awareness of regional priorities, they are likely to be better decisions and can allow more appropriate policy responses to be designed' (HM Treasury, 2004: 1.1). Indeed, the enhanced roles of the GOs and Assemblies can be interpreted as a way of achieving greater horizontal co-ordination between regional strategies and within regional networks and ensuring that territorial interests are more fully represented in Whitehall. In the same way that the Westminster model epitomised an era of 'government', so Rhodes's 'differentiated polity model' describes an era of 'governance', a new form of co-ordination mechanism in which central government is only one of many policy actors (Amin and Hausner, 1997; Rhodes, 1997).

Not all commentators, however, are convinced by this 'quantum leap'. Though acknowledging that government may be in a state of transition, they conclude that the centre may be extending rather than yielding its repertoire of control and influence by 'developing new means through which to achieve co-ordination, steering and gate-keeping' (Bache and Flinders, 2004: 106). The notion that the 'state-centric and constitutional perspective has been almost replaced by an image of government in which institutions are largely irrelevant...is exaggerated at best and misleading at worst' (Peters and Pierre, 2004: 75). Structural inequalities between government tiers enable Whitehall departments to regulate governance by retaining control over resources and key policy decisions, limiting the capacity of regional actors to co-ordinate their activities and shape national policies to the needs of their territories (Marsh et al, 2003). Evidence for this lies in the growing importance attached to regional and local delivery targets, agreed between the Treasury and delivery departments, and the creation of new co-ordinating units and task groups to administer national policies at sub-national level (Cabinet Office, 2002; Davies, 2002; Morgan, 2001; Bache, 2000; Holliday, 2000; Rhodes 2000a). While espousing subsidiarity the government can be accused of adopting a fragmented approach in which Whitehall departments have pursued distinct and uncoordinated approaches to decentralisation.

The objective of this article is to explore these contrasting accounts of the emerging relationship between Whitehall and the key regional institutions. In particular, it examines whether regions have merely become useful conduits for the delivery of central government policies and targets or whether they have emerged as venues for promoting a more holistic approach to strategy making. It 
draws specifically on a series of semi-structured interviews with senior civil servants in each domestic Whitehall department, but is also informed by interviews with senior staff in the key regional institutions. Interviews were conducted between Autumn 2002 and Spring 2004. Staff from the Local and Regional Government Research Unit in the Office of the Deputy Prime Minister advised on the choice of Whitehall interviewees. All interviews were undertaken under Chatham House Rules to ensure anonymity.

We begin by briefly examining the key institutions that comprise the regional system of governance. Second, the extent of the linkages between central government departments and these institutions is explored. Third, we investigate how far the strengthening of the regional tier is expressed in policy priorities that are embedded in national and regional strategies and the extent to which regional bodies have secured increased discretion over policy and the use of resources. Fourth, we assess responses within central government to demands to 'join up' those government policies that have a regional dimension. Finally, we reflect on evidence of Whitehall's changing relationships with the English regions.

\section{Regional institutions}

It is increasingly acknowledged that policy-making and service delivery based around Whitehall departmental structures and boundaries are unable to respond to the complexity of crosscutting issues associated with regions and localities. The Cabinet Office report, Reaching Out observed, 'The tiers of central government that impact on the regional level are highly fragmented, not able to deal with cross-cutting issues well, and generally do not have sufficient influence over central policy design and implementation' (Cabinet Office, 2000a: 1.13). The outcome was a twin track approach. First, to promote a more holistic approach to regional governance, more Whitehall departments were persuaded to establish a GO presence, which were given additional powers to coordinate programme activities and discretion over how to achieve results. Second, Whitehall coordination of those policy initiatives that have a specific regional dimension was to be strengthened and greater account taken of the strategic outcomes of central government initiatives affecting regions. The consequence has been growing interest in developing the vertical connections between national and sub-national tiers and the horizontal connections between policy areas. Vertical decentralisation has been applied to those policies with a strong territorial impact: economic development, employment, housing, rural, spatial planning, transport and the environment, which has prompted calls for greater strategy co-ordination at the regional level. 
The eight Government Regional Offices have become Whitehall's key representatives in the regions and are regarded as a crucial mechanism for policy co-ordination and delivery. Ten Whitehall departments now sponsor GO activities, compared with only three in 2001. GOs are expected to contribute to some forty 'high level' government targets, manage annual expenditure of some £9bn, tackle cross-cutting issues and help co-ordinate policy delivery. Each sponsor department contributes to administrative costs in direct proportion to their financial contribution. Significantly, however, each retains control over its programme funding. In addition a Regional Co-ordination Unit (RCU), based in the Office of the Deputy Prime Minister (ODPM), was established in 2001 as a 'hub' to support the GO network and facilitate a more corporate approach to regional issues across Whitehall.

In 1998 the RDAs were created to assist in strengthening regional economic performance, achieve regionally balanced growth and tackle intra-regional economic inequalities. Accountable to the Secretary of State for the DTI, RDA's have a $£ 2$ bn annual budget comprising contributions from the ODPM (75\% of funding) DTI, DfES, DEFRA and DCMS. In 2002, and again in 2004, RDAs were given additional resources and greater discretion over their use, together with new responsibilities for tourism and transport, the delivery of rural policies, skills and business support. These were matched by tough and tightly monitored sets of government imposed targets and milestones. RDAs are also to ensure that their strategies and activities fit in with the wider framework of regional strategies, notably Regional Planning Guidance (RPG) (DETR, 2002). RDAs can be regarded, therefore, as a step towards decentralising decision-making over economic policy, in which regions will have increasing freedom, flexibility and funding to exploit their indigenous sources of growth, but tied to stronger accountabilities and performance incentives (HM Treasury, DTI and ODPM, 2004).

The 1997 White Paper, Building Partnerships for Prosperity, setting out the Government's plans for RDAs, also proposed the creation of nominated Regional Chambers (DETR, 1997). While RDAs would be principally responsible to ministers, Chambers (subsequently renamed Assemblies), representing local authorities and regional economic and social interests, would act as a counterbalance to RDAs by making them regionally accountable for their activities (Snape et al, 2003). Assemblies are also expected to provide a forum for regional representatives to engage with GOs and other regional government bodies, prepare regional spatial and housing strategies, coordinate regional strategies and present an independent voice on behalf of their regions. Nonetheless, they have no statutory or real decision-making powers and rely on influence with other regional bodies to deliver their objectives. Compared with the elected bodies elsewhere in the 
UK their joint resource base is also limited, less than $£ 30 \mathrm{~m}$ annually and, though in receipt of local authority subscriptions, are increasingly reliant upon closely supervised and contingent ODPM funding (Jeffery and Reilly, 2004).

A measure of central government's dominance is the extent of its control over public expenditure in the regions. A recent study in the West Midlands revealed that of the $£ 22$ bn public expenditure identified during 2001-02, some 95\% was provided directly or indirectly by central government. Social security and health accounted for almost half and local government for a further quarter. Local government is dependent, however, upon central government for some $75 \%$ of its expenditure and ministers influence many of the decisions about how those resources should be assigned (Ayres and Pearce, 2002). A significant proportion of expenditure - some $£ 13.5 \mathrm{~b}$ - was allocated through the 'jig-saw' of NDPBs and executive agencies, a layer of regional administration appointed by and directly accountable to ministers. This labyrinthine group of bodies has increased in number and influence, but the precise scale of their activities is uncertain, indeed 'there is no formal map of the disposition of NDPBs ... and quangos at sub-national and regional level throughout the UK' (House of Commons Public Administration Select Committee, 2001). Following the Chapter 2 agenda efforts are being made to co-ordinate the activities of these bodies through the GOs. Nonetheless, because they are primarily concerned with means rather than policy aims, which are determined by their parent departments, NDPBs are ill-equipped to develop innovative approaches or align their activities to meet regional priorities.

This brief examination suggests that though steps have been taken to boost regional institutional capacity, central government has been able to mobilise its extensive powers and resources to safeguard control. Developing relationships may have created superficial opportunities for 'active subsidiarity' at the regional level, but suggestions that they challenge the authority of the centre are unsafe. In effect we may be witnessing two familiar forces at work; the decentralising of limited decision making and responsibility for delivery, combined with measures to maintain control over key policy areas within Whitehall departments.

\section{Links between the 'centre' and regions}

Effective governance is more than about institutional design. It involves the management of process, the interactions and relationships between different actors in complex networks and relationships (Flinders, 2002; Kickert et al, 1997). Institutional reforms should be accompanied by mechanisms for communication and information exchange between the centre and key regional institutions. Our interviews confirmed that prior to 1997, beyond a small group of departments 
concerned with urban regeneration, land use planning, economic development and culture, there was very limited awareness in Whitehall about the regional dimension. Indeed, it had taken some time for civil servants to determine what Labour's agenda for decentralisation was about and how they should develop and participate in new or existing networks of relationships with the regions. Several triggers induced a change in perceptions. They included the growing stress placed upon region based public service targets. Second, the decision to increase the number of departments sponsoring GO activities to improve policy delivery, especially in areas which span departmental boundaries. Third, the growing emphasis placed by the Treasury on the need to tackle regional economic disparities (HM Treasury and DTI, 2001) and, fourth, an emerging recognition that some policy flexibility is required to take account of regional diversity. Finally, the publication of the English Regions White Paper, which opened up the prospect of greater accountability through political devolution, raised awareness of the regional tier across Whitehall

The outcome is that most departments have established new or expanded existing teams to administer various aspects of the emerging regional agenda, including ensuring departmental interests are reflected in GO annual business plans, participating in RCU meetings and responding to regional submissions to the spending review process. The civil servants interviewed generally welcomed the opportunities to establish links with regional bodies and were alert to the regional dimension of work in their own and other departments. How far this awareness is embedded more generally in Whitehall is less certain and we were invariably advised that, despite ministerial rhetoric, traditional Whitehall working methods continued to squeeze out a regional perspective. Indeed, apart from negotiations around the White Paper, 'decisions about the devolution of functions have been taken in the absence of any real template against which you can take consistent decisions at the centre' (DEFRA official). Departments were following independent agendas and approaches to decentralisation appeared idiosyncratic, with some departments focussing on regional structures (ODPM, DTI, DCMS), while others (DoH, DfES) had largely bypassed the regional tier in favour of sub-regional or local bodies. The consequence, according to a DfES official, was 'increased duplication of effort and confusion at the centre', with 'too many organisations vying for political position and influence over the policy process'.

Most civil servants attributed their increased contacts with regional institutions to the growing responsibilities of the GOs. A DEFRA official observed that 'the department is far more exposed to external networks and working relationships than under its predecessor MAFF' which, until 2002, had resisted engagement in the GOs and, like the Home Office, was still adjusting to its new GO role. New, government inspired, regional and sub-regional strategies had also encouraged civil 
servant to communicate with their regional colleagues to gather information and feedback on implementation issues. Whitehall civil servants viewed the expertise and personalities of key individuals in the regions as crucial, reflecting the view that effective governance is dependent upon 'soft' process measures, inter-personal relationships and trust (Rhodes, 2000b).

'There is a need to improve mutual understanding and open up organisational cultures between the Government Offices and the centre. There should be greater opportunity for people at the centre to spend time in the regions, and vice versa. Increased face-to-face contact when working on specific policy projects is vital' (Cabinet Office and ODPM, 2002:30).

Such contacts were seen as beneficial in transferring knowledge and expertise, though officials acknowledged that available staff resources limited engagement beyond the GOs. The transfer of resources to GOs was seen as a way of fostering speedier and more effective delivery and joined up working. Civil servants were mindful, however, that the GO's primary duty is to deliver PSA targets and, given the system of ministerial accountability, dangers could arise in transferring too much discretion over policy-making and delivery, particularly where responsibility is shared across departments. It was even insinuated that the new pedigree of Regional Office Directors, many of whom are not career civil servants, had introduced a group of potentially more independent minded officials who might at some stage stand up for their region's interests against a department or powerful NDPB.

One of the more remarkable features of the new regional institutional landscape is the 'RDAs absolutely unprecedented access to ministers among Quangos, including bilateral meetings between RDA chairs and the Prime Minister twice a year' (Treasury official). Ministers and civil servants, apart from those in the Department of Health and the Home Office which liase with the Agencies through their GO teams, have regular monthly meetings with RDA senior staff. Treasury officials had clear political instructions to press the regional agenda and develop personal relationships with RDA board members and senior staff. Reflecting the importance attached to their role in promoting regional economic development a Treasury official observed, 'RDAs attend our monthly meetings and key RDA personnel have access to our senior officials on a one-to-one basis. If they have a voice we certainly have an ear'. Some delivery departments had expressed unease about the increased flexibility given to RDAs, fearing they might pursue activities that would conflict with national policies. In this respect the Treasury, ODPM and the No 10 Office have played a pivotal role. An ODPM official observed, 'there's not an open door to Gordon Brown and John Prescott, but they provide very strong support [for RDAs] and I've seen the 
Treasury in meetings overcome some of the obstacles and difficulties that departments were raising about RDA activities'.

Groupings of local authorities played an important part in developing regional institutional arrangements during the 1990s and, in some regions, Chambers were established in advance of the government's proposal to create unelected regional bodies. Regional Assemblies are formally regarded in Whitehall as the legitimate representatives of the regions and a key point of reference for the GOs. Whitehall civil servants were hard pressed, however, to identify any direct links between their departments and these nominated bodies and most were unaware of the White Paper's proposals to enhance their strategy co-ordination role. ODPM ministers do have regular meetings with Assembly leaders and officials from the ODPM and the Department for Transport participate in the activities of the English Regions Network (ERN), the umbrella organisation for Assemblies established with ODPM support. In addition, civil servants from the ODPM and DfT have quarterly meetings with Assembly staff responsible for regional planning, transport and monitoring, which are seen as useful in exchanging information and providing feedback on the feasibility of government policy and guidance. In general, however, Assemblies were viewed as having limited capacity in terms of legitimacy, statutory powers, technical competence or influence. Furthermore, beyond the ODPM and DfT, civil servants' awareness of the ERN was scant. Overall, civil servants were under few pressures to pursue any direct relationship with Assemblies, preferring to work through the GOs, RDAs or their own regional agencies. Their restricted funding, delivery powers and the difficulties faced by any new institution in establishing a record of achievement, confirmed that unelected Assemblies are not yet well placed to persuade ministers that they should be granted additional powers and resources.

\section{Regional influence over policies and spending plans}

Recent developments may have strengthened the role of key regional institutions, but the real test of their effectiveness is the extent to which they are able:

- To develop regional policy priorities, which are embedded in national policy making,

- To prepare coherent regional strategies, and

- To secure increased discretion over the use of budgets.

In this section we examine these three key dimensions from a Whitehall perspective. 


\section{Developing and embedding regional priorities in national policy}

In 2001, the Government's annual spending review was replaced by a three year spending horizon in which resources were to be allocated on the basis of bilateral Public Service Agreements between the Treasury and spending departments. Cross cutting targets were also encouraged, involving several departments and their agencies, for example the agreement between the Treasury, ODPM and DTI to jointly promote economic growth in all parts of the UK, and to narrow the gap in growth rates between the regions. The Chancellor also inserted a regional dimension into the spending review process by confirming that,

'Regional institutions, such as the RDAs and the Government Offices, were being asked to consider the key strategic priorities for their regions to bring about increased economic productivity. This analysis will feed into departmental allocations and geographical priorities emerging from the 2002 Spending Review' (HM Treasury, 2001: 6.57).

The aim of this 'intelligence gathering exercise' was not to invite bids for additional resources, but to inform decisions about how mainstream spending might be modified to improve their effectiveness, including cross cutting measures and targets. GOs and RDAs subsequently submitted Regional Priority Documents to the Treasury and individual departments were to reflect on how these might be addressed in their spending plans.

'I'm hoping the regional input will increase as time goes on and the process is refined. We are hoping to change people's thoughts from how much they get to what they are able to deliver. We want to challenge people and ask them what will we get for this? Where good cases are being made they may get more funds' (Treasury official).

The Treasury's message was unambiguous, but officials in spending departments were circumspect about the impact of regional inputs on departmental priorities. 'They can influence in a modest way, they can make representation and they may or may not get listened to. They certainly can't control Whitehall in any way' (DoT official). A DfES civil servant was even more cautious,

'If you're talking about the real world, they [GOs] have limited influence. In theory, they are supposed to have a lot of influence but, because of the way they work, because they're unable to demonstrate their added value, they don't have credibility in the system. Without that it's very difficult to have influence.' 
Alongside measures to sensitise programmes to regional priorities, in 2002 the Treasury requested all spending departments to identify expenditure on a regional basis. Funding transparency is regarded as essential in gauging how far resource allocations reflect territorial priorities. But, as McLean's recent work to identify EU and national flows of public expenditure on a regional basis reveals, the process is far from straightforward (McLean, 2003). A DTI official confirmed these difficulties and also drew attention to the potential political consequences.

'They [the Treasury] asked every department to describe the regional impact of its expenditure and we all found that terribly difficult. In DTI we've broken up areas of the department and looked at bits of this or that budget and where does it go in regional terms.

The Treasury wants us to go further and get every department to track its expenditure in regional terms. That's something we're trying to build into our thinking but the Treasury is consciously or unconsciously unlocking a box that could be controversial.'

Despite the difficulties of encouraging departments to adopt a regional perspective, the Treasury is continuing in its efforts to incorporate a regional dimension into Whitehall policy making. To inform the 2004 spending review process Regional Assemblies, GOs and RDAs were invited to prepare Regional Emphasis Documents (REDS) (HM Treasury, 2003). These were to indicate how existing government spending and intervention might be refocused, to increase their respective impacts against government objectives and targets for increasing regional productivity and growth and improving social and environmental sustainability. The Treasury anticipates that regional institutions will also assist departments as they plan how to implement their targets, which could provide for more flexibility and differentiation between regions and feed into local authority financial settlements (HM Treasury, 2004).

\section{Preparing regional strategies}

The regional tier has become a focus for measures to improve productivity, reduce economic disparities, promote sustainable forms of development, regenerate urban and rural areas and develop cultural and creative interests. (Cabinet Office and DTLR 2002; HM Treasury, 2002; HM Treasury, and DTI 2001). The consequence has been a range of regional strategies prepared by a variety of regional bodies. Through decentralisation, the Labour Government can be seen to be devising new tools for governance which should provide the regional tier with increased opportunities to formulate policies (6 et al, 2002). Central government retains control, however, over the scope and content of the key regional strategies. For example Regional Planning Guidance, and its constituent Transport and Waste Disposal Strategies, is prepared by Assemblies 
but issued by the ODPM. Referring to the engagement of regional bodies in RPG, an ODPM official also drew a clear distinction between their participation in regional policy making and their capacity to influence spending plans.

'Local authorities, business and voluntary groups now have an opportunity that they have never had before [to influence plans]. But when it comes to spending priorities the Secretary of State has to consider first of all the overall budget and second national priorities. In that context what can be done to amend the plans to reflect regional priorities is limited.'

Similarly, Regional Economic Strategies and Frameworks for Employment and Skills Action are drawn up by RDAs, but subject to Whitehall approval. While central government can claim to have made regional policy making more inclusive, regional strategies remain securely anchored to national priorities. Furthermore, some regional strategies are viewed as more significant than others.

'Some of the strategies are very specific and have operational consequences, like the RES. The RDAs will publish priorities about where they will direct their investment and that has a real world impact. By contrast, a Regional Sustainability Development Framework doesn't directly lead to any real world consequences. It succeeds, if at all, in the influence that it has on other people and organisations' (DEFRA official).

In general Whitehall officials agreed that regional institutions have adequate intellectual and research capacity to prepare regional strategies. Doubts were expressed, however, about their ability to co-ordinate and take them forward to implementation. Particular concerns were expressed about the technical competencies of the Assemblies, which were only granted government funding in 2001. RDAs were also treated with some suspicion in terms of their mix of capabilities and people to manage the complexity of regional economic agendas.

'The problem is that the RDA's work isn't about direct project delivery it's about how you influence and work with people. There's still doubt about whether they have the capacity and people to fulfil this role, leading some to question the quality of the Regional Economic Strategies' (DTI official). 
Officials in other departments also had reservations about the quality and contents of regional strategies. A DfES official was critical, 'In terms of the skills strategies being prepared...from the first cut there is no added value, no innovatory ideas, no bottom up solutions, but we have hope.'

\section{Securing discretion over the use of budgets}

A key measure of the autonomy available to regional institutions is the discretion they have over the use of their budgets. Both the GOs and RDAs have exerted pressure on Whitehall departments to allow them to adapt funding regimes to meet regional priorities and so enhance the delivery of national policies. In April 2002 this achieved some success in the form of a 'single pot' of funding for RDAs, which brought together the separate budgets of the DTI, the (then) DETR and DfEE. The Agencies were granted some flexibility to vire resources between programmes, subject to them meeting 'stretching outcome and output targets to ensure their activities deliver their strategic goals, matching flexibility with greater accountability' (HM Treasury 2000: 3.67). The outcome was that host teams in sponsor departments came to better understand what RDAs were trying to achieve, both in terms of individual programmes and securing a more cohesive approach to performance management. Its immediate impact was to enable civil servants to agree to proposals that were unacceptable only a few months before.

'Comparing the RDA's financial management and controls and discretion two years ago and now you will see dramatic change which had given rise to opportunities for innovation and pressures on the centre to meet regional priorities' (RCU official).

A DTI official drew attention, however, to the difficulties in ensuring that the new thinking permeated departments.

'It was amazing that they [departments] moved to the single pot so quickly. To move from tight monitoring to look at outcomes and worry less about how they're achieved is a huge cultural change for departments. But the RDAs should remember that they have a customer in their parent departments and there are pressures from within this department to impose our very specific targets.'

The GOs are officially viewed as a single government resource at the regional level. Reaching Out envisaged a more holistic approach by integrating the regional activities of Whitehall departments through the GOs and giving the Offices more discretion on how to achieve results (Cabinet Office, 2000a). Views about the impact of these reforms varied; a Treasury civil servant confirmed that 'the GOs are still feeding very much into their own sponsor departments - the funding streams are 
still very persuasive'. Conversely, an ODPM official emphasised the growing capacity of GOs to align spending on related programmes and achieve policy synergies.

'The GOs bring together at least half of Whitehall's departments and are able to deliver programmes on the ground. That didn't happen before. The barriers are breaking down quite substantially, if you look at how they work now compared to five years ago you'll see that the silos have substantially been eroded.'

Chapter 2 of the White Paper spelt out a new role for the GOs to chair Inter Agency Working Groups, comprising NDPBs, to examine ways of co-ordinating policies with a regional dimension. For the most part this was judged by civil servants as a GO initiative, rather than part of the Whitehall agenda and its impact was anticipated to be limited.

'A lot of policies are delivered through NDPBs and hopefully they are joining up with GOs.

We are trying to nudge them in that direction but it's not always straightforward. Sometimes they have their own institutional jealousies and territoriality' (DEFRA official).

Though apparently committed to giving greater weight to regional priorities there remain profound ambiguities in the Government's approach. It is looking to the regions to improve the delivery of national targets and is encouraging regional institutions to generate regional solutions and apply greater discretion over policy implementation. In practice, however, the institutions have limited opportunities to turn regional strategy into delivery because of the restraints imposed by national targets and funding streams. The consequence is a 'catch twenty-two' in which Whitehall remains suspicious about decentralising further powers and resources to a tier that has yet to demonstrate its competencies.

\section{Joining up the regional agenda at the centre}

'Joined up working' has become a fashionable term to describe the co-ordination of activities across organisational boundaries. Real world problems often do not easily fit within the boundaries of individual government departments, but decentralising or delegating functions in pursuit of greater service efficiency and productivity cannot be effective in the absence of co-ordination between and within government tiers (Stoker, 1999). New Labour's response to the challenges of co-ordination across Whitehall departments and between government tiers emerged following the publication of Reaching Out and Wiring It Up (Cabinet Office, 2000a, b). Both studies concluded that problems of policy co-ordination arose from the dominance of functional over territorial 
concerns and confused accountabilities within central government. At the regional level institutional structures had evolved incrementally and were hindering efforts to tackle a range of policy challenges. This critique spawned a spate of activity including the creation of the Regional Co-ordination Unit, which was to act as the interface between departments and the GOs and a conduit by which departments would be informed about how their policies were working in practice. It would also bring GOs and departments together in a simple and effective way, but 'it will not replace existing networks where they work well' (RCU, 2001:3.4). GOs were to become actively involved in developing those policies that have a significant regional dimension or where they could contribute through their knowledge of local delivery.

Interviews with government officials revealed a distinct divide between those who regarded the RCU as useful in facilitating the development of delivery mechanisms with the GOs and those who judged that its added value, in terms of 'joining up', was limited. The former group viewed the Unit as a useful 'shop front' for the GOs by which responses to a range of policy documents could be fed back to the centre. The RCU was praised for encouraging the GOs to examine their activities in a more holistic way, rather than as a series of separate, departmental sponsored programmes. Some officials, however, were more cautious about the Unit's value.

'I would say that the RCU has broadly encouraged more joined up working but there is a long way to go. In large parts of this department we are starting from a negligible base, but at least people are talking to each other now' (DERFA official).

The RCU was censured for not promoting itself and working to develop links and confidence in its capabilities with government departments. Some officials felt that it had very little to offer their departments in terms of assisting their relationship with the regions, preferring to rely upon established bilateral links with GOs. 'The RCU is an important secretariat or resource management tool but that's it' (DTI official). The Unit's effectiveness depends crucially on the support and commitment of ministers and senior civil servants and faces the inevitable problems associated with any cross-departmental unit attached to a specific department.

Though officially committed to inter-departmental collaboration several civil servants described it as difficult and time consuming, a distraction or an additional burden. We were also advised that departmental targets were not always consistent, hindering joint working. Some officials questioned the added value of collaboration and were wary of investing resources in crossdepartmental issues with a regional dimension. Moreover, while welcoming the increased presence of departments in the GOs and the opportunities it afforded to promote increased flexibility in 
approaches to cross-cutting issues, this was offset by anxieties that such measures might compromise departmental priorities and targets. The danger is that if civil servants are simply going through the motions of joining up, the prospects for co-ordination at the regional level are diminished and, though regional institutions may seek to apply cross cutting methods, they will be thwarted because Whitehall departments are unable to respond. 'If people are having to give priority to the requirements of the centre, which may be at odds with the regional agenda then clearly they can't join up whether they want to or not' (DfT official). Such concerns underscore the difficulties in facilitating co-ordination at the regional level in the absence of more fundamental changes to government budgetary and accountability systems and lack of effective co-ordination within the Whitehall machine (Flinders, 2002). Many of the problems and issues diagnosed in Reaching Out and Wiring It Up are still clearly evident. As the Prime Minister recently observed, 'Too often government's structures reflect vested interests and tradition. Departmentalism remains strong in Whitehall - usually too strong - and the allocation of ministerial portfolios sometimes unhelpfully reinforces these barriers' (Blair, 2004).

Coherence in the process of territorial development is also hampered by the tendency for decisions about policy and delivery at the regional level to be taken incrementally. Individual departments are seen to be pursuing decentralisation through new regional institutions and strategies without sufficiently examining how delivery might be achieved through existing structures. The overall impression is that Whitehall departments are 'pumping up' regional institutions to promote their own policy and delivery agendas. The Sustainable Communities Plan, for example, which has huge resource and spatial planning consequences, was published without proper inter-departmental working to determine its strategic implications and was accompanied by conflicting messages about how resources might be used (ODPM, 2003). Similarly, the recent Haskins Review of Rural Delivery also expressed concerns about the duplication and confusion of delivery roles at the regional level (Haskins, 2003). The Barker report on housing markets also observed that, despite the presence of Regional Planning Bodies, Regional Housing Boards and Regional Development Agencies, 'no organisation has overall ownership of the regional housing market ... Greater integration between the various regional strategies and the bodies that produce them would seem desirable' (Barker, 2004: 2.16-2.17). The preferred solution, however, was not to build on the mutually supporting roles of the GOs and Assemblies to co-ordinate government policies in the regions and integrate regional strategies. Rather, an additional layer of administration was proposed in which Regional Planning Bodies and Housing Boards would be merged and new 'independent' Regional Planning Executives created to inform the provision of market housing and investment in social housing. 


\section{Conclusions}

This account of institutional developments in the English regions provides an interesting view from a Whitehall perspective. As such it may not be an entirely accurate interpretation, but it does reflect the judgements of senior civil servants whose role it is to manage the process of multi-level working. Viewed from Whitehall the regional institutional landscape in England has clearly become far more crowded since 1997 and, at first sight, regional institutions seem to have greater freedoms and autonomies and opportunities to influence national policy decisions. Alongside the ODPM, the Treasury has supported the enhancement of regional structures and spending departments have been drawn, some grudgingly, into the process of regional working. GOs, RDAs and Assemblies have been invited to participate in national spending reviews and government departments have been cajoled into examining regional priorities in the context of their spending programmes, expressing their expenditure on a regional basis and co-operating on policies which have a territorial dimension.

Conversely, Labour's term of office has seen central government reinforce its own presence and influence in the regions. The creation of the RCU can be judged as a measure of Whitehall's desire to improve the delivery of its own policies in the regions. The funding flexibility granted to RDAs has attracted particular attention and is perceived in Whitehall as representing a significant administrative and cultural shift. Nonetheless, RDA discretion over the use of resources remains circumscribed by national targets and accountabilities. The GOs have also been granted additional funding and are charged with fostering policy co-ordination. Their resources remain tied, however, to Whitehall funding streams and the GO's principle task is to meet programme targets set by sponsor departments. Despite the expectations set out in Chapter 2 of the English Regions White Paper, GOs are not yet perceived in Whitehall as having the tight coherence that makes for a strong co-ordination role.

One of the more intriguing outcomes of recent reforms has been the Treasury's invitation to regional bodies to participate in the spending review process. Government departments remain reluctant, however, to incorporate regional priorities into their policies. Regional institutions have also been encouraged to prepare a multiplicity of regional strategies and the GOs and Assemblies are expected to instil a more corporate approach to regional policy making and implementation. Strategies are prepared, however, firmly within the confines of national priorities, targets and funding regimes and some are subject to ministerial approval. Indeed, from a Whitehall perspective, granting regional institutions greater discretion over the content of strategies could 
lead to contradictions in the way government funding and accountability chains work. While apparently pledged to subsidiarity, there is limited evidence that ministers have fully digested the consequences of increased regionalisation for the machinery of government. Indeed, a sceptic might view the proliferation of strategies as evidence of individual government departments vying to advance their own separate agendas, rather than a measured attempt to promote policy integration. The absence of elected regional government and fragmented interests within regions also frustrate the formulation of a clear and consistent regional view. In these circumstances Whitehall civil servants can readily disregard pressure from beneath to adjust policies to meet regional priorities.

Those observers who perceive the process of regional decentralisation ushering in a more dispersed form of government can be comforted by evidence that dialogue between staff in Whitehall and regional institutions has intensified. This is crucial in communicating understanding of government policies, ensuring that Whitehall staff better understand regional circumstances and building trust. The level of engagement, however, varies between departments and regional institutions, depending on how long organisations have been in place, departmental approaches to decentralisation and the legacy of regional working. Many civil servants in most domestic spending departments have regular, direct communication with staff in the GOs and ministers and senior civil servants in the DTI, Treasury and ODPM, have frequent meetings with RDA board members and senior staff. By contrast, apart from the ODPM, contacts between ministers and civil servants with Assembly members and staff are infrequent, underlining the limited role of Assemblies.

Fashion may dictate that central government's bureaucratic silos have become 'anachronistic' (Ling, 2002: 624), to be replaced by models that emphasise partnerships, networks and trust. Compared, however, with the broad constitutional reforms introduced elsewhere in the UK it would be wrong to conclude that the drive towards a multi-level, networked form of governance in the English regions has yet supplanted the Westminster-Whitehall model. Civil servants may be more familiar with the potential benefits of co-ordination across policy areas and between government tiers, but accountability mechanisms discourage cross-departmental collaboration and territorial flexibility. Responsibilities for delivering services may now be shared with regional partners but, only when regional institutions are able to demonstrate 'credibility' and 'value added' will Whitehall acquiesce to the transfer of powers and resources. Bache (2000: 589) perceives the importance of policy convergence, 'or, perhaps more accurately, the absence of policy conflict' as a crucial factor in determining how far central government will allow policy networks and subnational organisations to run their own affairs. While decentralising responsibility for delivery Whitehall continues to hold the purse strings, retains for itself the power to define the policy 
agenda and maintains control by seeking to join up the activities of multiple service deliverers at the centre (Pierre, 2000).

The Government's approach to English regionalism was reflected in the negotiations around the White Paper, which was the fruit of what was politically acceptable, rather than a radical and overarching vision of future inter-governmental relations. Effectively there was a meeting of minds between New Labour and Whitehall. Strong regional government would be counter-intuitive for both (Sanford, 2002). Further administrative decentralisation will only be endorsed in those policy areas the government considers a 'safe bet', where there will be the least challenge to the centre. As a civil servant observed, 'the government has dipped its toe in the water of decentralisation very gradually and has been pleasantly surprised by the way it's worked'. Whitehall officials have so far been able to pursue their relationships with the regions on a piecemeal basis and, perhaps to their relief, the prospect of elected regional government has retreated. Nonetheless, opposition to political devolution should not be used as a justification for ministers and civil servants to ignore their responsibilities for applying a more effective form of government at the regional level. Indeed, they have a central role to play in improving the co-ordination of national policies with a regional dimension, aligning the delivery of policies administered by a plethora of region based, government bodies and taking account of regional priorities and diversity in the implementation of national and regional policies.

\section{Acknowledgement}

Research for this article was funded through the Economic and Social Research Council's Devolution and Constitutional Change Programme, 'Emerging patterns of governance in the English regions' based at Aston Business School, Grant Number L219521113.

\section{Note}

The empirical evidence for this article is principally drawn from interviews conducted with civil servants in the Home Office, Treasury, the Departments for Culture, Media \& Sport (DCMS), Environment, Food \& Rural Affairs (DEFRA), Education and Skills (DfES), Trade and Industry (DTI), Transport (DfT), Work \& Pensions (DWP), Health, the Office of the Deputy Prime Minister (ODPM) and the Regional Co-ordination Unit (RCU). All interviews were undertaken under Chatham House Rules. 


\section{References}

6, P., Leat, D., Seltzer, K. and Stoker, G. (2002) Towards holistic governance: The new reform agenda, Palgrave, Basingstoke.

Amin, A. and Hausner, J. (1997) Beyond market and hierarchy: Interactive governance and social complexity, Edward Elgar, Aldershot.

Ayres, S. and Pearce, G. (2002) Who governs the West Midlands? An audit of government institutions and structures, West Midland Constitutional Convention and West Midland Regional Assembly, Birmingham.

Bache I. and Flinders, M. (2004) 'Multi-level governance and British politics', in Bache, I and Finders, M. (Eds.) Multi-level governance, Oxford University Press, Oxford, 93-106.

Bache, I. (2000) 'Government within governance: Network steering in Yorkshire and the Humber', Public Administration, vol 78, no 3, 575-592.

Barker, K. (2004) Delivering stability: Securing our future housing needs, HM Treasury, Stationery Office, London.

Blair, T. (2004) Prime Minister's speech on reforming the civil service, $24^{\text {th }}$ February, 10 Downing Street, London.

Cabinet Office and Department for Transport, Local Government and the Regions. (2002) Your region, your choice: Revitalising the English regions, Stationery Office, London.

Cabinet Office and Office of the Deputy Prime Minister. (2002) Incorporating regional perspectives into policy making, Stationery Office, London.

Cabinet Office. (2000a) Reaching out: The role of central government at the regional and local level, Performance and Innovation Unit, Stationery Office, London.

Cabinet Office. (2000b) Wiring it up, Whitehall's management of crosscutting policies and services, Performance and Innovation Unit, Stationery Office, London.

Cabinet Office. (2002) Reconnecting departments and their agencies, Stationery Office, London.

Davies, J. S. (2002) 'The governance of urban regeneration: A critique of the governing without government thesis', Public Administration, vol 80, no 2, 301-322.

Department of the Environment, Transport and the Regions. (1997) Building partnerships for prosperity: Sustainable growth, competitiveness and employment in the English Regions, HMSO, London.

Department of the Environment, Transport and the Regions. (2002) Supplementary guidance for the Regional Development Agencies in relation to the regional economic strategies, DETR, London.

Flinders, M. (2002) 'Governance in Whitehall', Public Administration, vol 80, no 1, 51-75.

Haskins, C. (2003) Rural delivery review: A report on the delivery of government policies in rural England, DEFRA, London.

HM Treasury and Department of Trade and Industry. (2001) Productivity in the UK 3: The Regional Dimension, Stationery Office, London.

HM Treasury. (2000) Pre budget report: Building long-term prosperity for all, Stationery Office, London. 
HM Treasury. (2001) Pre budget report: Building a stronger, fairer Britain in an uncertain world, Stationery Office, London.

HM Treasury. (2002) Opportunity and security for all: Investing in an enterprising, fairer Britain, New Public Spending Plans 2003-2006, Stationery Office, London.

HM Treasury. (2003) Spending review 2004: Regional emphasis documents, Letter to Government Office Directors, Regional Development Agency Chief Executives and Regional Assemblies, London.

HM Treasury. (2004) 2004 Spending review: Meeting regional priorities, Stationery Office, London

HM Treasury, Department of Trade and Industry and Office of the Deputy Prime Minister. (2004) Devolving decision making: 2 - Meeting the regional economic challenge: Increasing regional and local flexibility, HMSO, London.

Holliday, I. (2000) 'Is the British State hollowing out?' The Political Quarterly, vol 71, no 2, 167176.

House of Commons Public Administration Select Committee. (2001) Mapping the Quango State, Fifth Report, (HC - 367), Stationery Office, London.

Jeffery, C. and Reilly, A. (2004) Funding Regional Assemblies: Issues and challenges, Report for the English Regions Network, German Institute, University of Birmingham.

Jessop, B. (1999) 'The dynamics of partnership and governance failure', in G. Stoker, G. (Ed.) The new politics of British local governance, Macmillan, London, 11-32.

John, P. (1996) 'Europeanization in a centralizing state', in Jeffery, C. (Ed.) The regional dimension of the European Union: Towards a third level in Europe, Frank Cass, London, 131-146.

Kickert, W. J. M., Klijn, E. H. and Koppenjan, J. F. M. (1997) Managing complex networks, Sage, London.

Klijn, E. H. (2002) 'Governing networks in the hollow state', Public Management Review, vol 4, no 2, 149-165.

Ling, T. (2002) 'Delivering joined up government in the UK: Dimensions, issue and problems', Public Administration, vol 80, no 4, 615-642.

Marks, G. and Hooghe, L. (2000) 'Optimality and authority: A critique of neo-classical theory', Journal of Common Market Studies, vol 38, no 5, 795-816.

Marsh, D., Richards, D. and Smith, M. (2003) 'Unequal plurality, Towards an asymmetric power model of the British polity', Government and Opposition, vol 38, no 3, 306-332.

McLean, I. (2003) Identifying the flow of domestic and European expenditure into the English regions, ODPM, London.

Morgan K. (2001) 'The new territorial politics: rivalry and justice in post-devolution Britain', Regional Studies, vol 35, no 4, 343-348.

Office of the Deputy Prime Minister. (2003) Sustainable communities: Building for the future, Stationery Office, London.

Peters, G. and Pierre, J. (2004) 'Multi-level governance and democracy: A faustian bargain', in Bache, I and Finders, M. (Eds.) Multi-level governance, Oxford University Press, Oxford, 75-92.

Pierre, J. (2000) Debating governance, Oxford University Press.

Pierre, J. and Peters, G. (2000) Governance, politics and the state, Macmillan, London. 
Prescott, J. (2003) Speech given by the Deputy Prime Minister, Campaign for the English Regions Conference, 24 February, ODPM, London.

Regional Co-ordination Unit. (2001) Reaching out: Action plan, DETR, London.

Rhodes, R. A. W. (1997) Understanding governance: policy networks, governance and accountability, Open University Press, Buckingham.

Rhodes, R. A. W. (2000a) 'The governance narrative: Key findings and lessons from the ESRC's Whitehall programme', Public Administration, vol 78, no 2, 345-363.

Rhodes, R. A. W. (2000b) 'New Labour's civil service: Summing up joining up', The Political Quarterly, vol 71, no 2, 151-166.

Richards, D. and Smith, M. J. (2002) Governance and public policy in the UK, Oxford University Press, Oxford.

Sanford, M. (2002) 'What place for England in an asymmetrically devolved UK', Regional Studies, 36, 7, pp. 789-796.

Snape, S., Ashworth, R., Aulakh, S., Dobbs, L. and Moore, C. (2003) The development of regional scrutiny: Final report, Institute of Governance and Public Management, Warwick University.

Skelcher, C. (2000) 'Changing images of the state: overloaded, hollowed-out and congested', Public Policy and Administration, vol 15, no 3, 3-19.

Smith, M. (1999) The core executive in Britain, Palgrave, Basingstoke.

Stoker, G. (1999) The new politics of British local governance, Macmillan, London. 